\title{
Research on M\&A Performance of Chinese listed TMT Companies
}

\author{
Liqi Liu \\ School of Economics \\ Jinan University \\ Tianhe District, Guangzhou, China
}

\begin{abstract}
The TMT industry is an emerging industry which links the telecommunication industry, the high-tech industry and the media industry on the basis of internet technology. In this paper, Principal Component Analysis (PCA) method is introduced to establish M\&A performance evaluation model for Chinese A-share TMT companies in order to measure the fluctuation of M\&A performances in Chinese TMT industry. It shows that the performance of the acquiring party increases before the M\&A while declines after the M\&A. The performances of most of the acquiring companies drop below the previous level after the M\&A, meaning that M\&A activities have no significant influence on improving the performances of the listed TMT companies in Chinese A-share market.
\end{abstract}

Keywords-TMT; M\&A; Company Performance; Principal Component Analysis

\section{INTRODUCTION}

TMT (Telecommunication, Media, Technology) industry is an emerging industry which links the telecommunication industry, the high-tech industry and the media industry on the basis of internet technology.

With the gradual improvement of the laws and regulations in M\&A market, Chinese enterprises are growing rapidly through M\&A activities. In the meanwhile, Chinese TMT industry is also accelerating industry integration through mergers and acquisitions.

With the rapid development of the Chinese M\&A market and the accelerating industrial integration, it is necessary to review and analyze the impact of M\&A activities on performances of these TMT companies in order to better guide M\&A activities in Chinese TMT industry.

\section{REVIEW ON RELATED RESEARCHES}

\section{A. Event Study Methods}

\section{1) Foreign Researches}

Jensen and Ruback[1] (1983) conducted a study of 13 researches published in 1970s and found that shareholders of the target corporates receive an excess return between 20 and 30 percent. Schwert[2] (1996) studied 1814 M\&A cases happened between 1975 and 1991 and the result shows that the cumulative abnormal return of the acquiring company is around $35 \%$ in the event window. Moeller and Schlingemaim[3] (2008) conducted a study of 12,000 acquisitions between 1980 and 2004, and concluded that the acquired firms receive a gain of $1.1 \%$ on average.

\section{2) Domestic Researches}

In a comprehensive and systematic analysis of 1216 M\&A samples of Chinese listed companies from 1993 to 2002, Zhang[4] (2003) concluded that M\&A activities have positive effect on the performance of target companies. Liu[5] (2010) studied Chinese M\&A cases in 2006 of all securities firms, and found that the acquirers and their shareholders gain expected benefits in the short term while the impact is unconfirmed in the long run.

\section{B. Financial Analysis Methods}

1) Foreign Researches

Using 233 M\&A cases from 1964 to 1971 in UK as samples, Meek [6] (1987) found that the ROA of the acquiring companies shows a downward trend and reaches the bottom in the fifth year after the transaction. Healy, Palepu, and Ruback[7] (1992) studied the largest 50 M\&A transactions in the United States between 1979 and 1984, suggesting that the industry-adjusted performances of the combined firms improve due to the transactions. Megginson and Morgan[8] (2007) introduced a financial analysis method to study 35 cases in America and concluded that there is a significant improvement in production capacity and business performance of the companies after M\&A.

\section{2) Domestic Researches}

Li, Wang, Zeng, Chen and Zhu ${ }^{[9]}(2004)$ analyzed 84 M\&A transactions conducted between 1999 and 2001 by introducing 9 financial indicators to evaluate company performances, finding that performances improve in the first year after the transaction and earnings of companies decline after this year. Zhao and Li[10](2008) studied 39 M\&A cases and selected 6 financial indicators as evaluation variables in their research, which suggests that neither values of the companies nor the shareholders experience significant changes.

\section{DATA AND VARIABLES}

M\&A cases in this paper are mainly collected from the Choice Financial Database and samples are selected among acquirers successfully completed the transaction between 2009 and 2013 according to the following rules: (1) According to CITIC industry classification standards, select samples of A-share market among communication, media, computers, electronic components and other high-tech industries; (2) Available financial data covering two years before and after the M\&A; (3) The acquirer must be a TMT company; (4) Eliminate companies that have been specially processed (ST or 
PT); (5) Eliminate samples consists of incomplete or abnormal data. Taking into account the above settings, 71 samples are collected, among which there are 57 samples in computer and high-tech industries, 6 samples in media and 8 samples in telecommunication.

TABLE I. PERFORMANCE INDICATORS SYSTEM

\begin{tabular}{ccc}
\hline Dimensions & Indicators & No. \\
\hline Profitability & Return on Net Assets & X1 \\
Asset & Return on Total Assets & X2 \\
Quality & Total Asset Turnover & X3 \\
Debt Risk & Current Assets Turnover & X4 \\
& Debt Assets Ratio & X5 \\
Operating & Current Ratio & X6 \\
Growth & Growth Rate of Main Business Revenue & X7 \\
\hline
\end{tabular}

To build a performance index system for the acquiring TMT firms, 8 financial indicators from 4 dimensions are introduced according to "Enterprise Performance Evaluation Standard Value 2015" specified by the SASAC of the State Council (Table.1).

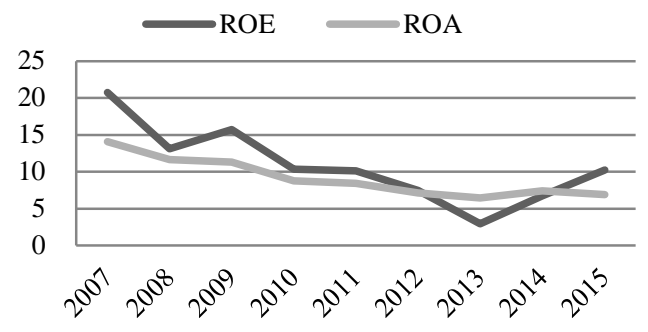

Fig. 1. Trend of Profitability

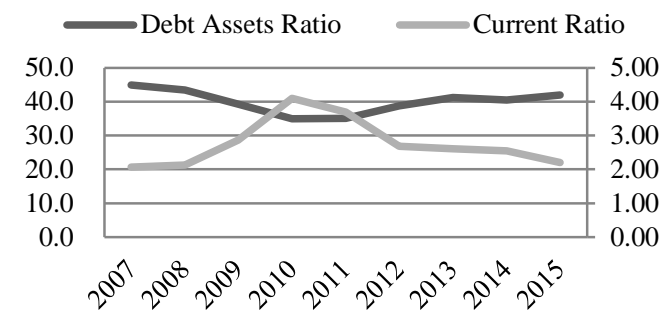

Fig. 3. Trend of Debt Risk

\section{EMPIRICAL ANALYSIS}

\section{A. Research Method}

At present, there are two main methods in M\&A performance study: Event Study and Financial Analysis. However, China has a relatively short history of securities market and the stock prices are more likely to be manipulated. In addition, a certain proportion of non-tradable shares in a vast majority of Chinese listed companies also make it much difficult to evaluate company performances. Besides, any manipulation of accounting indicators can only be temporary, changes in corporate performances will eventually be reflected in their accounting statements if given a long enough accounting period.

Based on the above reasons, the paper applies a Financial Analysis Method in the performance analysis.

\section{Descriptive Statistical Analysis}

Since $77 \%$ of the sample cases are occurred between 2011 and 2013, this period can be defined as the "Active Period". Take this period as a reference, we can conclude as follow:

(1) Profitability: ROA and ROE of the samples show a continuous decline trend before the M\&A active period, and begin to recover after the period (Fig.1);

(2) Asset Quality: Current asset turnover and total asset turnover of the sample are gradually declining during 2007 and 2015, but the fall begins to slow down after the active period (Fig.2);

(3) Debt Risk: Current Ratio shows a rapid growth before the active period while begins to decline after the period; Debt Asset Ratio starts to rise after the period (Fig.3);

(4) Operating Growth: The revenue growth rate of the samples fluctuates around 22\% from 2007 to 2015 while the profit growth rate experiences more fluctuations and begins to increase substantially after the active period (Fig.4).

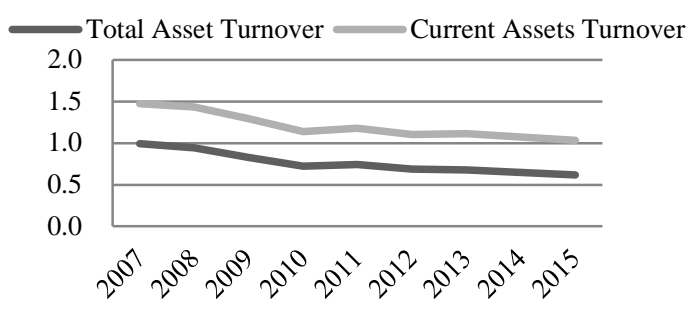

Fig. 2. Trend of Asset Qualit

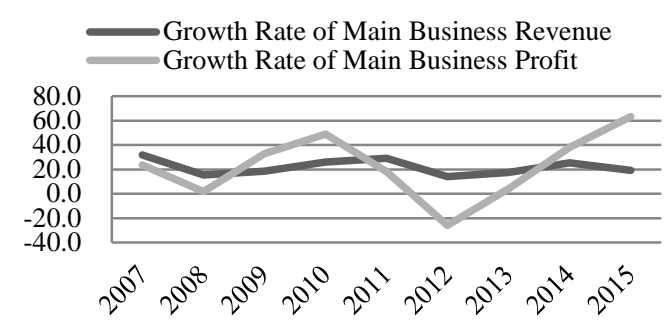

Fig. 4. Trend of Operating Growth

\section{B. Modeling}

Principal Component Analysis (PCA) can reduce the dimension of the data with the loss of less data by means of orthogonal transformation and help researchers build up a more reasonable evaluation system. The application of this method is as follows:

(1) Select the data of variables $X_{1} \sim X_{8}$ from all sample acquiring companies in a given year;

(2) Orthogonalize all the data in order to meet the conditions of PCA and mark the processed variables as $\mathrm{X}_{1}^{\prime} \sim \mathrm{X}_{8}^{\prime}$; Let $\mathrm{L}_{j}(\mathrm{j}=1,2,3 \ldots, \mathrm{r})$ represent the original value of a specific financial indicator, $\operatorname{Max}\left(\mathrm{L}_{j}\right)$ represent the maximum value of the same specific indicators, $\mathrm{k}$ represents the annual average value of the same indicator in a given year, $\mathrm{M}_{j}$ 
represent the orthogonalized reverse indicators and $\mathrm{N}_{j}$ represent the orthogonalized positive indicators:

$$
\begin{gathered}
M_{j}=\max \left(L_{j}\right)-L_{j} \\
N_{j}=\max \left|L_{j}-k\right|-\left|L_{j}-k\right|
\end{gathered}
$$

(3) Use PCA method to extract principal component factors $\mathrm{Y}_{i}(\mathrm{i}=1,2,3, \ldots, \mathrm{n})$; Define $\mathrm{A}_{i}(\mathrm{i}=1,2,3, \ldots, \mathrm{m})$ as contribution rates of variance of principal components, $S_{j}(j=1,2,3 \ldots, r)$ as performances scores in any M\&A year of the enterprises:

$$
\mathrm{S}\left(\mathrm{j}_{t}\right)=\sum_{i=1}^{n} A_{i} Y_{i} / \sum_{i=1}^{n} A_{i}
$$

(4) On the basis of the results in Step(3), we can further calculate the average annual performances of the sample TMT enterprises in Year $t$ by using the following equation:

$$
\mathrm{S}(\mathrm{t})=\sum_{1}^{r} S_{j t} / \mathrm{r}
$$

(5) Further discussion can be conducted based on the performance evaluation results obtained through the above analysis processes.

\section{Process of Analysis}

The principal component analysis is carried out on SPSS 22.0. As the PCA processes are similar in different years across the M\&A cycle, this paper will only show the analysis process on the year of M\&A as an example and analysis on other years can refer to this example.

\section{1) Data Orthogonalizing}

As the asset-liability ratio and current ratio are indicators of reversion and moderation while other indicators are positive indicators, data must be orthogonalized before the principal component analysis. Here we use (1) and (2) to orthogonalize the original data and remark the 8 variables as $X_{1}^{\prime} \sim X^{\prime}$.

\section{2) PCA Applicability Analysis}

According to result of the KMO and Bartlett test, the statistic value in the KMO test is $0.621(>0.5)$ and the Sig. value in Berlett's Test of Sphetical is $0.00(<0.05)$, which means the sample data are in line with the requirements of PCA method.

\section{3) Principal Components Extraction}

According to the results of the PCA, the original 8 indicator variables are replaced by 3 new component variables (Table 3). These 3 variables explain $70.65 \%$ of the total variance and have strong description ability of corporates performances. The contribution rate of main components variance differs among these 3 variables: With a rate up to 44.49\%, Component1 $\left(\mathrm{Y}_{1}\right)$ is the first component and mainly explains the performances of $\mathrm{X}_{2}, \mathrm{X}_{3}$ and $\mathrm{X}_{4}$; Component2( $\left.\mathrm{Y}_{2}\right)$ has a rate of $33.84 \%$ and mainly explains $\mathrm{X}_{4}$ and $\mathrm{X}_{5}$; Variance contribution rate of Component $3\left(\mathrm{Y}_{3}\right)$ is $21.67 \%$ and this component mainly explains $X_{8}$.

Using (3), we can build the performance model of the M\&A year for the acquiring party:

$$
\mathrm{S}\left(\mathrm{j}_{\mathrm{t} 0}\right)=0.44 \cdot \mathrm{Y}_{1}+0.34 \cdot \mathrm{Y}_{2}+0.22 \cdot \mathrm{Y}_{3}
$$

$Y_{1}, Y_{2}$ and $Y_{3}$ respectively represent to performance scores of Component1 3 and coefficient relationship with $\mathrm{X}_{1}^{\prime} \sim \mathrm{X}_{8}^{\prime}$ can be represented by the eigenvectors of the principal components.

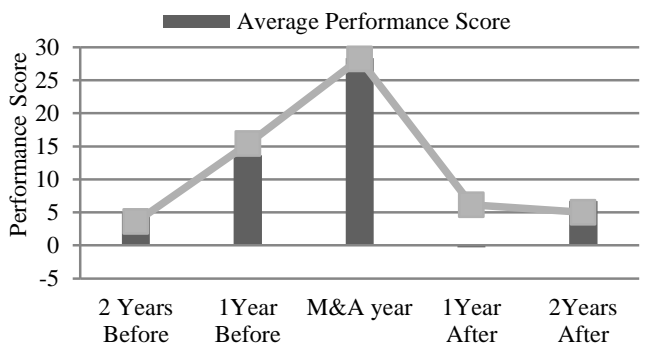

Fig. 5. Changes of Performances in the 5-year M\&A Cycle

In the same way, we can build models of other M\&A years and then look into the trend of the average annual performances during the whole M\&A cycle. (Fig.5)

4) Result Analysis

As can be seen in Fig.5, the average performance rises continuously in the first two years before the M\&A and reaches the top in the $M \& A$ year. However, the score decreases significantly after the transaction and does not recover until the second year after the M\&A.

Besides, we also found that the average performance scores of $58 \%$ of our TMT sample companies drop below the previous level after the M\&A, which suggests that M\&A activities cannot significantly improve the performance of the listed TMT companies in Chinese A-share market.

\section{CONCLUSIONS}

In this paper, by introducing a financial index system and using the principal component analysis method, we establish a performance evaluation model to measure the changes in performances of Chinese A-share listed TMT companies during the 5-year M\&A period. From the results of the analysis, the following two conclusions are drawn:

Firstly, the average performance score of the acquiring TMT companies increases annually at a rate of $138.23 \%$ before the M\&A year. However, this performance improvement is not sustainable. Corporates performances of the overall sample showed a downward trend after the M\&A and the decline in the first year after the transactions is the most significant;

Secondly, M\&A activities have no significant effect on performances improvement of the Chinese A-share listed TMT acquiring companies, and the performances of over half of our sample are obviously lower than that before the M\&A.

M\&A activities usually consist of long operation cycle and many aspects of the process may affect the effectiveness of the M\&A. Thus, listed TMT companies should be more cautious in M\&A decision-making. Besides, relevant government departments should also speed up the improvement of regulations and policies in this field.

\section{REFERENCES}

[1] Jensen, M. and Ruback, R.S. The Market for Corporate Control: The Scientific Evidence [J]. Journal of Financial Economics, 1983, 11: 5-50 
[2] Schwert G.W. Mark-up Pricing in Mergers and Acquisitions[J]. Journal of Financial Economics, 1996, 41(2): 153-192

[3] Moeller S.B., Schlingemann F.P. and Stulz R.M. Firm Size and the Gains from Acquisitions[J]. Journal of Financial Economics, 2008,73(2): 201-228

[4] Zhang Xin. Does M\&A Create Value[J]. Economic Research Journal, 2003, 6: 20-29

[5] Liu Jun and Yu Pengyi. An Empirical Study on M\&A Effect of Domestic Listed Companies[J]. Shanghai Finance, 2010, 12: 42-45

[6] Meeks G. Disappointing Marriage: a Study of the Gains from Merger[M]. New York: Cambridge University Press, 1987: 67-89

[7] Healy P.M., Palepu K.G. and Rubaek R.S. Does Corporate Performance Improve after Mergers [J]. Journal of Financial Economics, 1992, 31(2): $135-215$

[8] Megginson and Moregan. Benefits of mergers[J]. Journal of Finance, 2007(3):12-13

[9] Li Shanmin, Wang Caiping, Zeng Zhaozao, Chen Yugang and Zhu Tao. Research on Long - term Performance in Asset Reorganization of Chinese Listed Companies[J]. Management World, 2004, 9: 131-136

[10] Zhao Hongying, Qi Xiaoyan, Li Jing and Hu Hanhui. An Empirical Study on the Impact of M\&A in Private Listed Companies on Financial Performance[J]. Journal of Central South University (Social Science Edition), 2008, 1: 89-94 